\title{
Use of trained dogs to determine the age structure and conservation status of kiwi Apteryx spp. populations
}

\author{
HUGH A. ROBERTSON and JAMES R. FRASER
}

\begin{abstract}
Summary
Specially trained dogs are used to locate many threatened bird species in New Zealand during conservation management and research projects. Systematic searches were made in four forest patches in Northland where many Brown Kiwi Apteryx mantelli had been fitted with bands, wing tags, transponders or radio-transmitters over a 12-year period of experimental management. The percentage of subadult birds found by dogs increased in line with predictions from population models of the changing age structure of the population. The dogs independently found radio-tagged adults and subadults in close proportion to their known abundance. Dogs proved to be an excellent tool to determine the age structure of a kiwi population. With knowledge of the life history of the species involved, this information was used to make an accurate assessment of the conservation status of the study population of Brown Kiwi in Northland. Our results also support the recent downgrading of Little Spotted Kiwi Apteryx owenii from 'Vulnerable' to 'Near Threatened', which was based partly on healthy age ratios found during dog searches on Kapiti Island, rather than on results from a study of their breeding biology on the island which showed unsustainably low chick recruitment.
\end{abstract}

\section{Introduction}

All five species of kiwi Apteryx spp. were classified as threatened (BirdLife International 2000, Tennyson et al. 2003), with major reductions in both the range and numbers of all species on the mainland of New Zealand over the past 100 years; however, the Little Spotted Kiwi has recently been re-classified as 'Near Threatened' (BirdLife International 2008).

Since 1991, considerable governmental and public conservation effort has been directed at determining the threats to kiwi, and then managing those threats. The critical factor in the demise of kiwi has been identified as predation by introduced mammals, especially predation of juvenile kiwi by Stoats Mustela erminea, and predation of adult kiwi by dogs Canis familiaris and Ferrets Mustela furo (McLennan et al. 1996). Efforts to control Stoats and Ferrets through trapping or poisoning, and control of dogs through advocacy to dog owners, have led to some managed Brown Kiwi Apteryx mantelli populations starting to recover (H. Robertson unpubl. data).

Because kiwi are nocturnal, cryptic, and hard to catch and then re-catch for traditional capturerecapture studies, the tools available to measure the population trends and conservation status of kiwi populations have been limited to timed call counts and population modeling based on the analysis of radio-telemetry data. Call counts have been used to assess general population trends of Brown Kiwi in Northland in relation to management efforts (Pierce and Westbrooke 2003), and call counts are used to monitor population trends for all taxa elsewhere as part of a nationwide call count scheme. The methodology requires considerable effort by a large number of people, and because of the large number of variables affecting call rates from night to night and year to year, 
call counts are unlikely to provide more than a broad picture of the population trends in a particular area. The method is particularly effective in detecting sudden declines in populations (brought about by high adult mortality) but is less effective at determining increases (due to delayed maturity and onset of calling). It has strength in assessing regional trends, especially in moderate to high density populations such as those investigated by Pierce and Westbrooke (2003). Management projects on kiwi generally use radio-transmitters on adults and their offspring to help measure response to management actions (e.g. McLennan et al. 1996, Robertson et al. 1999), however, this method is expensive and labour-intensive, but clearly provides excellent data for use in population models, and can be applied to a broad range of population densities.

Dogs that are trained specially to find and indicate the location of kiwi are the main tool used to help locate and mark birds in research studies, especially when an unbiased sample of the population is required. The other main tool for catching kiwi, the broadcast of kiwi calls or making simulated calls from a shepherd's whistle, and then hand-capture of birds that approach, has a distinct bias in favour of catching territorial males.

Colbourne (1992) used the high ratio of juveniles to adults (41\% of 87 birds, based on bill length and weight) found by his dog in daytime shelters on Kapiti Island between 1986 and 1990 to argue that Little Spotted Kiwi Apteryx owenii were doing well on the island. These data were used to classify the species as 'Vulnerable', due to its small area of occupancy (Birdlife International 200o), rather than as 'Endangered' or 'Critically Endangered' based on population projections including poor chick recruitment rates observed during a study of their breeding biology on Kapiti Island (Jolly 1989).

McLennan and Potter (1993) pointed out their concerns about the conservation status of the various species of kiwi on the mainland of New Zealand from the very low ratio of juveniles to adults ( $3 \%$ of 63 birds) found by six different dogs during in their research projects around the country.

In this study, we extend this previous work by using an already well marked and studied population of Brown Kiwi to assess whether the dogs used to help locate and mark a kiwi population can also be used to reliably assess the age structure of a population, and hence determine its conservation status. If dogs detect young and adult kiwi in direct proportion to their abundance, then the conservation status of a population can be determined; a kiwi population that is increasing would be expected to have a higher proportion of young birds in it than a population which is declining.

Clearly, an important issue for this technique is that juveniles and subadults can be reliably distinguished from adults. Kiwi have no plumage variation with age; however, they have exceptionally slow growth rates and do not reach final size until 3-5 years old (Heather and Robertson 2005). Young kiwi that have been sexed from the mtDNA in their feather bases (Huynen et al. 2003) can be reliably identified as subadults from their bill length for the first 3 years, but those aged over 3 years old remain difficult to distinguish from adults without repeated measurements taken over a few months to determine if they are still growing.

\section{Methods}

\section{Study area}

The study was done in four remnant patches of podocarp-broadleaf forest within $8 \mathrm{~km}$ of Purua $\left(35^{\circ}\right.$ $37 \mathrm{~S}, 174^{\circ}$ o $8 \mathrm{E}$ ), in central Northland, New Zealand (Figure 1 ). The four forest patches ranged from 35 to 110 ha; Purua (11o ha) and Rarewarewa ( 55 ha) were centred on old volcanic cones, Riponui (45 ha) was on the side of a low ridge and deeply incised by a series of parallel streams, and Hodge's Bush (35 ha) was in a broad valley. The main canopy tree in all patches was Taraire Beilschmedia taraire, with lesser amounts of Towai Weinmannia silvicola, Kohekohe Dysoxylum spectabile, Hinau Elaeocarpus dentatus, Karaka, Corynocarpus laevigatus and Puriri Vitex lucens, with the odd emergent Totara Podocarpus totara, Rimu Dacrycarpus dacrydioides and Kauri Agathis 


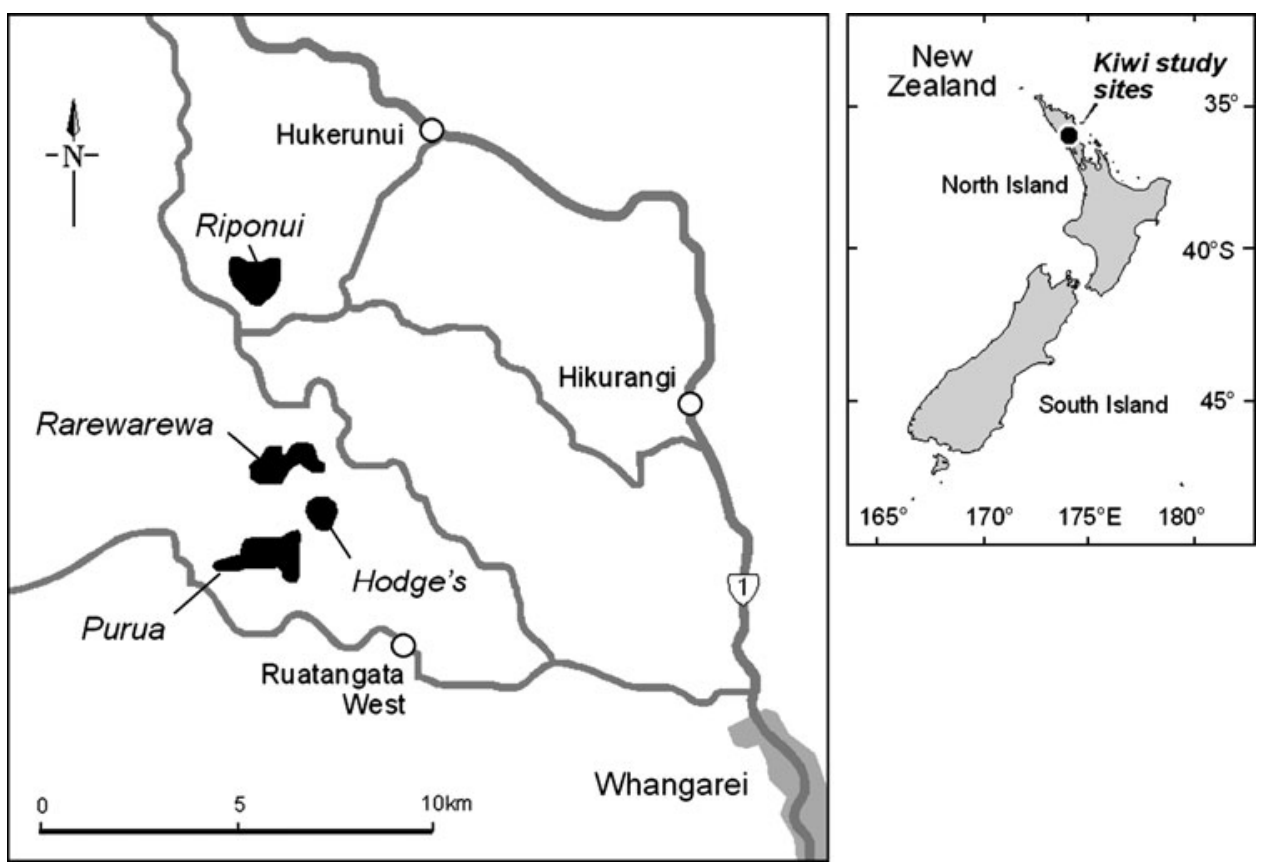

Figure 1. Map of the Purua area of Northland showing the four kiwi study sites searched with trained dogs.

australis that had escaped being logged in the early 190os. A few small plantations of young Radiata Pine Pinus radiata were growing next to the forest margins. Most kiwi lived within these four forest patches and their adjacent pines, but some radio-tagged birds used dense vegetation in riparian margins of streams flowing through farmland, or burrows in surrounding pasture and scrub patches, for daytime shelters. Ground cover in the forest patches varied from minimal in one patch that was grazed until the late 1990s, to heavily overgrown with Parataniwha Elatostema rugosum, Kiekie Freycinetia banksii, Supplejack Ripogonum scandens and ferns in damp gullies and faces.

An adaptive management study began in 1994 at the four study sites with the aim of determining and experimentally managing the introduced mammals that are the main threats to kiwi. Between 1994 and 2001, predator trapping, pest poisoning, and Operation Nest Egg (see Colbourne et al. 2005) resulted in population recovery, whereas kiwi declined in non-treatment sites (H. Robertson unpubl. data). Since 2001, predator trapping, especially targeting Stoats, has been done in all four forest patches and in the farmland in between, and this has led to recovery of the kiwi population throughout (H. Robertson unpubl. data).

\section{Dog searches}

In New Zealand, dogs are often used to assist with wildlife conservation programmes, either to locate particular threatened species (birds, lizards, or plants), or to locate particular pests. For 'bird dogs', the dog is initially trained to find hidden feathers of the target species (or a group of species such as kiwi). After 6-12 months of training, the Department of Conservation tests the temperament of the dog and if suitable, certifies that it and its handler can work on a particular species recovery programme. Although different breeds of dog have different scenting abilities, and search in different ways (e.g. labradors work close to their handler whereas setters range wider) 
and so may vary in their encounter rates, their ability to detect birds of different genders or age classes should be similar.

Two labradors, specially trained to find kiwi in their daytime dens, were used by Rogan Colbourne and HAR to find birds at the beginning of the study. Most birds were found in May and June 1994, except the sample from Hodge's Bush which was obtained in September 1994 and May 1995. The dogs indicated the daytime location of kiwi, which were then caught by hand. The birds were usually sheltering in a burrow, hollow log, or under dense vegetation; however, juveniles $(<1000 \mathrm{~g})$ rarely used burrows. The bill length and weight were recorded to help to determine the sex of the bird, because among adults there is no overlap in bill length between the sexes within a population of Brown Kiwi, and females are generally heavier than males (Heather and Robertson 2005). Most subadult birds were of indeterminate gender because, at that time, DNA sexing techniques for kiwi (Huynen et al. 2003) had not been developed. All adult males and some adult females and subadults were marked with radio-transmitters and metal leg bands covered with combinations of coloured reflective tape; the rest of the birds were banded or wingtagged for individual identification. Pairs were marked with the same colour combination, but on different legs; however, it subsequently proved difficult to always determine which leg was visible when only a reflective band was visible deep in a burrow. The original sample has been added to over the years with further kiwi found by dogs, with partners of radio-tagged birds, and with chicks followed since they left their nests. These birds have been banded or transpondered for individual identification, and the sex and age of most birds have been determined from measurements, behaviour and/or mtDNA sexing of feather samples.

By 2004, both labradors used at the start of the study had died, and so JF did systematic daytime searches through the four study areas with an English setter that had been certified to work on kiwi. Between mid-May and early July 2004, a systematic search was done to ensure an even coverage of the habitats within each of the four forest patches. The search was done without prior knowledge of the recent locations of radio-tagged birds. JF carried a GPS receiver with external aerial to plot the route taken, and the locations of each bird found each day. He attempted to search the steep and rough terrain with no more than $100 \mathrm{~m}$ between search paths (Figure 2). He also recorded the times spent searching for and handling birds, and the GPS calculated the length of route searched each day, although the dog would have covered very much more ground either side of the route than the actual distance walked. Even though many study birds were radio-tagged, JF carried a radio-receiver (without aerial) only to check on the identity of birds discovered without having to remove them from their daytime shelter and disturb them unnecessarily. All new birds found were measured, weighed and then banded or had a transponder inserted, and some were also radio-tagged. Feather samples were collected for DNA sexing (Huynen et al. 2003) from any bird of uncertain gender.

The systematic search was repeated two years later by JF and the same dog, between mid-May and the end of June 2006. Again, JF carried a GPS receiver to plot the route taken and the locations of birds, and a radio-receiver without aerial. The search was again done without prior knowledge of the recent locations of radio-tagged birds.

\section{Analysis of data}

We firstly compared the age ratios between the three samples to see if the ratio of young birds to adults detected in the population had changed over time following successful pest control and Bank of New Zealand Operation Nest Egg ${ }^{\mathrm{TM}}$ (see Colbourne et al. 2005) management carried out in all four study blocks during the previous decade.

We then compared the age distribution found by dogs to the expected age distribution in the population. At the start of the study, we assumed that the expected age distribution in a previously unmanaged population would be the same as the stable age distribution generated by population modeling in Excel PopTools, from the productivity and survivorship data observed in nontreatment blocks between 1994 and 2000 (H. Robertson unpubl. data). In the 2006 survey, we 


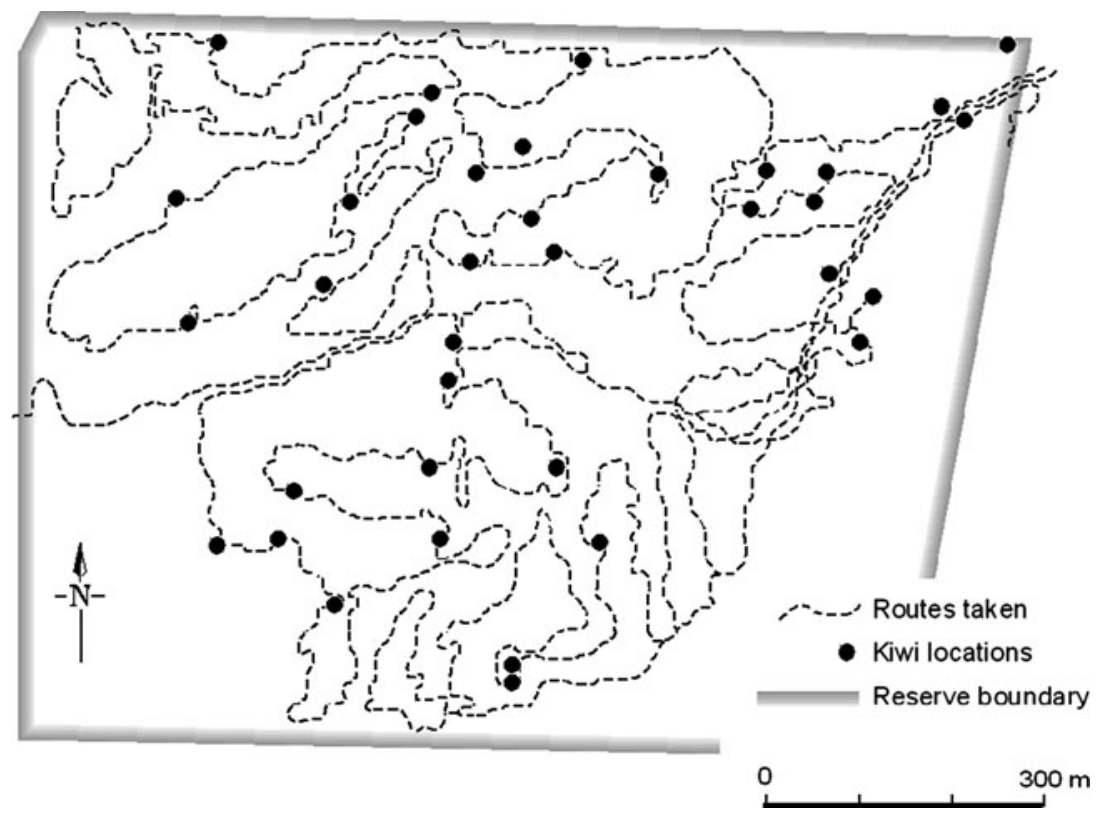

Figure 2. Map of Purua Scenic Reserve (75 ha) showing the routes taken over five days and the locations of 36 kiwi found by the trained dog in May 2006.

compared the age distribution found with the stable age distribution generated by PopTools, from productivity and survivorship data collected since 2001, when predator trapping began through 8, ooo ha, encompassing all four study blocks and surrounding farmland ( $\mathrm{H}$. Robertson, unpubl. data). Because most sampling was done in May and June, well after the main period of chick mortality in December through March (H. Robertson, unpubl. data), we assumed that most mortality of kiwi chicks from the current season (ages O-1 year) had already happened. We therefore estimated the expected number of birds aged o-1 years would be higher than the number of $1-2$ year old birds alive by the same ratio found between $1-2$ year olds and 2-3 year olds, rather than as the number of birds in Stage I (O-I years) estimated using PopTools. Because management practices had changed only relatively recently when the 2004 sampling was done, we could not generate an expected stable age distribution, but we expected it to be intermediate between the pre-treatment and post-trapping samples.

Finally, we investigated from the 2004 and 2006 samples whether the dogs detected radiotagged adults and young birds in proportion to their abundance in the population by comparing the number of radio-tagged birds found belong to each cohort with the number of radio-tagged birds available in the searched area at the time.

\section{Results}

\section{Dog searches}

Between 2 January 1994 and 31 May 1995, 110 different kiwi were found on 36 different dates, but no record was kept of the hours spent searching, nor of the distance traveled during those searches. Up to 11 birds were found and processed on a single day. Over $60 \%$ of the birds were found between mid May and the end of June, with most of the rest being found in September 1994, when Hodge's Bush was added to the study. The dogs found 94 different adult kiwi ( 49 males and 45 females), including 21 pairs found together; 12 subadults ( $>1000 \mathrm{~g}$ ) and four juveniles (297-810 g). 
Between 18 May and 6 July 2004, there were 85 encounters with 77 different kiwi in 105.5 hours of searching on 25 different days. Up to six birds were found and processed on a single day. The dog found 46 adults (24 males, 21 females and 1 colour-banded adult of unknown sex in a deep burrow), including five pairs found together; 28 subadults, and three juveniles (840-96o g).

Between 16 May and 29 June 2006, 141 encounters were made with kiwi in 80.6 hours of searching (105 km of walking) on 21 days. Up to 11 different individuals were found and processed on a single day. On 13 occasions, the bird(s) either ran off, or were too deep in a burrow or under-runner to determine their identity. Of the 128 encounters where the bird was identified, 111 different individuals were involved. The dog found 57 adults ( 28 males, 28 females and one colour-marked bird too deep in a hollow log to determine if it was male or female), including nine pairs; he also found 45 subadults and nine juveniles (590-88o g).

\section{Age structure}

There was a highly significant change in the ratio of young (juvenile and subadult) kiwi to adult kiwi found by the dogs between the three surveys. Before pest management began, $15 \%$ of the initial sample were young kiwi; by 2004, the sample consisted of $40 \%$ young kiwi, and by 2006 , after up to 10 years of conservation management, $49 \%$ of the birds found by the dog were young birds $\left(\chi_{2}^{2}=30.6, P<0.001\right)$.

Population modeling, using PopTools with a correction to account for mortality of juvenile birds $(<6$ months old ) before searches were done in May-June, showed that the stable age distribution of the unmanaged and declining kiwi population at the time of our initial sample should have contained $19 \%$ young birds. After five years of trapping pests, the modeling showed that the rapidly increasing population should have contained $55 \%$ young birds in May-June 2006 (H. Robertson, unpubl. data). In both cases, the age distribution observed was similar to that predicted from the population models (Binomial test: $z=-1.19, P=0.234$, and $z=-1.35, P=0.179$ respectively).

\section{Detection of radio-tagged birds}

In 2004, the dog detected $16(36 \%)$ of 44 adult kiwi (3 females and 41 males) and nine (24\%) of 38 subadults or juveniles which were wearing functioning radio-transmitters in and around the study areas. The ratios of radio-tagged adults and young birds found were not significantly different $\left(\chi_{1}^{2}=1.55, P=0.214\right)$.

In 2006, the dog detected 19 adults, 17 subadults and three juveniles wearing functioning transmitters, plus two adults whose transmitters had failed. At the time of the searches, 48 adult kiwi, 40 subadults and eight juveniles in the study blocks were wearing functioning transmitters, and so $40 \%$ of radio-tagged adults, $43 \%$ of subadults and $38 \%$ of juveniles were found by the dog. After combining juvenile and subadult samples, there was no significant difference in the ability of the dog to detect adults and young kiwi $\left(\chi^{2}{ }_{1}=0.043, P=0.835\right)$.

\section{Discussion}

Specially trained kiwi dogs have now been used as a valuable tool in research and management projects on kiwi for over 20 years. We have demonstrated here that their value extends beyond the initial location of birds for capture or recapture, speeding up searches for radio-tagged birds by pinpointing them when radio-telemetry had led the searchers to the bird's general location, and for finding particular birds whose transmitters had failed or fallen off.

Dogs detected radio-tagged birds of different ages in the population in close proportion to their known abundance, and also in close proportion to the expected frequencies of adults and subadults, derived from population modeling, in both the initial unmanaged population and in the 
later managed population. This means that the dogs showed no particular bias towards finding juvenile kiwi, which den mainly on the surface under dense vegetation during the day and are less tied to a territory than adults, which are more often found in burrows.

Jolly (1994) had earlier speculated that dogs had a bias towards finding juvenile Little Spotted Kiwi on the surface to explain why Colbourne's (1992) dog had found such a high proportion of juveniles on Kapiti Island. From our study, it seems likely that the dog had found adult and juvenile Little Spotted Kiwi in true proportion to their abundance. This result supports Colbourne's (1992) conclusion that Little Spotted Kiwi had good recruitment on Kapiti Island, which contrasted with an earlier study (Jolly 1989) which showed serious recruitment failure due to egg predation by Weka Gallirallus australis. Partly using Colbourne's (1992) data, BirdLife International had ranked Little Spotted Kiwi as 'Vulnerable' (BirdLife International 2000) rather than as 'Endangered' or 'Critically Endangered'. Given our findings, and the successful establishment of new populations derived from Kapiti Island (Colbourne \& Robertson 1997; H. Robertson and R. Colbourne, unpubl. data), it is reasonable that the species has now been further downgraded to 'Near Threatened' (BirdLife 2008).

The surprising result from our work is that during earlier research work only $3 \%$ of birds found by trained kiwi dogs on the mainland of New Zealand were juveniles (McLennan and Potter 1993). This low percentage of juveniles could be partially explained if adults in their study locations were very long-lived and had a low reproductive rate. Despite the searches being done 'more-or-less randomly, letting the dogs dictate the direction of travel', perhaps some of the areas to be searched in sparse populations had been selected after the resident adult birds had been heard calling in particular locations on previous nights. An additional, but probably minor, effect is that adults are often not found independently because pairs sometimes share daytime shelters, and they also share territories year-round, and so having found one bird of a pair, the other adult can be expected to be found somewhere nearby. Paerata Reserve at Tangiteroria, southern Northland, was a key site worked by McLennan and Potter (1993), and it yielded just one juvenile from 48 captures of 26 Brown Kiwi, rather than the five (19\%) individuals we would have expected in an unmanaged Brown Kiwi population in Northland. This was perhaps an early sign that the population was in trouble, because the population has subsequently fallen from $c$. 50 pairs in 1985-1991 (McLennan and Potter 1993) to none heard in 8 hours of night-time listening in 2003 (Glen Coulston, pers. comm.). Even though no independent juvenile Great Spotted Kiwi was recorded among 45 birds found by dogs at Saxon River, in northwest Nelson (McLennan and Potter 1993), the population has apparently remained stable over the last 15 years (Robertson et al. 2005), and so the conservation status of a species can not always be readily discerned from age ratios without a good knowledge of the life history, especially the longevity of adults, of the particular species involved.

The technique of using dogs to accurately determine the age structure and hence conservation status of a kiwi population will work effectively only in an area where a minimum of 30 independent encounters could be expected during a search. The key to the technique is that it is done either randomly or in a systematic way, rather than searching in sites where birds have been seen or heard beforehand. Likewise it is especially important not to target particular sites or habitats where birds are likely to congregate, such as areas of rank long grass or young pines and slash at the fenced edge of reserves which are more favoured by juvenile and subadult Brown Kiwi. We chose to search systematically with a GPS receiver to make sure that routes covered most of each forest patch, there were no large gaps in coverage, and routes did not overlap significantly between different days. Nevertheless, our coverage remained incomplete judging by the only moderate percentage $(36-40 \%)$ of resident radio-tagged adults found during the searches. Because the searches aimed to cover as much ground as possible in a relatively short time-span before the breeding season, many birds would have been missed if they happened to be sheltering well off the search paths at the time of the search, especially if they were in burrows or in patches of dense vegetation on nearby farmland rather than in the forest on the day in question. From the ratio of radio-tagged to untagged adults encountered, and the percentage of 
radio-tagged adults found, we estimated that the resident population in the four study blocks was about 70 pairs, or about one pair per 3.5 ha. The density of about 1.1 birds ha $^{-1}$, including subadults and juveniles, is exceptionally high compared with most kiwi populations around New Zealand, and so in lower density populations, it would take much longer to achieve good sample sizes.

A major problem faced in interpreting this type of data is the ability to accurately identify the sexes and ages of the birds encountered. Sexing kiwi is now done routinely from mtDNA sexing of feather samples (Huynen et al. 2003); pairs found together can be sexed from measurements as there is no overlap in bill length of adult kiwi within a population (Heather and Robertson 2005); some adult females can be sexed from bill length if it is beyond the upper limit of bill lengths of known males in that population, and some males can be sexed if they have a brood patch. Once the sex of birds is known, the age can be more accurately estimated; however, it remains difficult to distinguish well-grown subadults from adults without prior knowledge of their life history, or without recapturing and re-measuring them several months later to determine if they were still growing or were fully-grown at their first capture. In our research, we often knew the exact ages of subadults encountered because they had been marked as chicks in the nest, or were known subadults from growth between repeated measurements beforehand or after the dogging samples. If other workers using this technique classify all adult-sized birds as adults, then some well-grown subadults will be misclassified; however, this will lead to a conservative estimate of the conservation status of the population being studied rather than an optimistic one. Indeed, some of the Little Spotted Kiwi classified as adults by Colbourne (1992) have proven, at subsequent capture (e.g. Colbourne and Robertson 1997), to have been well-grown subadult birds when they were first encountered, and so his interpretation of the healthy state of the species on Kapiti Island was slightly conservative.

We expect that this technique will have equal application to all species of kiwi. It seems likely that the technique can be applied to other species of territorial ground-dwelling or flightless birds, especially those with distinctive age-specific plumages or slow growth rates, which allow subadults to be distinguished from adults.

\section{Acknowledgements}

Funding for this work came from the Bank of New Zealand Save the Kiwi Trust and the Department of Conservation. Rogan Colbourne helped with the initial dog searches in 1994 and 1995. Sue Bell, Paul Cornille, Emma Craig, Clea Gardiner, Pete Graham, Pat Miller and Miriam Ritchie of the Whangarei Area Office of the Department of Conservation helped to establish and monitor the kiwi population used in this study. Bill and Joan Lovell allowed us access across their farm to the reserves and their private forest patches. Natasha Coad, Rogan Colbourne, Martin Jones, Stuart Marsden and Ray Pierce made useful comments on the manuscript.

\section{References}

BirdLife International (2000) Threatened birds of the world. Barcelona and Cambridge, UK: Lynx Edicions and BirdLife International.

BirdLife International (2008) BirdLife International's Data Zone. [http://www.birdlife. org/datazone/species/index.html, accessed on $10 / 6 / 2008]$.

Colbourne, R. (1992) Little Spotted Kiwi (Apteryx owenii): recruitment and behaviour of juveniles on Kapiti Island, New Zealand. J. Royal Soc. N. Z. 22: 321-328.
Colbourne, R. M. and Robertson, H. A. (1997) Successful translocations of Little Spotted Kiwi (Apteryx owenii) between offshore islands of New Zealand. Notornis 44: $253-258$.

Colbourne, R., Bassett, S., Billing, A., McCormack, H., McLennan, J., Nelson, A. and Robertson, H. (2005) The development of Operation Nest Egg as a tool in the conservation management of kiwi. Sci. for Conserv. 259. Department of Conservation, Wellington. 
Heather, B. D. and Robertson, H. A. (2005). The field guide to the birds of New Zealand. Auckland, New Zealand: Penguin.

Huynen, L., Lambert, D. M., McLennan, J. A., Rickard, C. and Robertson, H. A. (2003) A DNA test for sex assignment in kiwi (Apteryx spp.). Notornis 50: 231-233.

Jolly, J. N. (1989) A field study of the breeding biology of the Little Spotted Kiwi (Apteryx owenii) with emphasis on the causes of nest failures. J. Royal Soc. N. Z. 19: $433-448$.

Jolly, J. N. (1994) Populations of Little Spotted Kiwi on Kapiti Island: a response to Rogan Colbourne. J. Royal Soc. N. Z. 22: 329-331.

McLennan, J. A. and Potter, M. A. (1993) Juveniles in mainland populations of kiwi. Notornis 40: 294-297.

McLennan, J. A., Potter, M. A., Robertson, H. A., Wake, G. C., Colbourne, R., Dew, L., Joyce, L., McCann, A. J., Miles, J., Miller, P. J. and Reid, J. (1996) Role of predation in the decline of kiwi Apteryx spp., in New Zealand. N. Z. J. Ecol. 20: 27-35.

Pierce, R. J. and Westbrooke, I. M. (2003) Call count responses of North Island Brown Kiwi to different levels of predator control in Northland, New Zealand. Biol. Conserv. 109: 175-180.

Robertson, H. A., Colbourne, R. M., Graham, P., Miller, P. J. and Pierce, R. J. (1999) Survival of Brown Kiwi (Apteryx mantelli) exposed to brodifacoum poison in Northland, New Zealand. N. Z. J. Ecol. 23: 225231.

Robertson, H. A., McLennan, J. A., Colbourne, R. M. and McCann, A. J. (2005) Population status of Great Spotted Kiwi (Apteryx haastii) near Saxon Hut, Heaphy Track, New Zealand. Notornis 52: 27-33.

Tennyson, A. J. D., Palma, R. L., Robertson, H. A., Worthy, T. H. and Gill, B. J. (2003) A new species of kiwi (Aves, Apterygiformes) from Okarito, New Zealand. Rec. Auckland Mus. 40: 55-64

\section{HUGH A. ROBERTSON*}

Department of Conservation, P.O. Box 10-420, Wellington 6011, New Zealand.

\section{JAMES R. FRASER}

With a Nose for Conservation, 642 Ngunguru Rd, R.D.3, Glenbervie, Whangarei o173, New Zealand.

*Author for correspondence; e-mail: hrobertson@doc.govt.nz

Received 16 November 2007; revision accepted 10 June 2008 